This item was submitted to Loughborough's Research Repository by the author.

Items in Figshare are protected by copyright, with all rights reserved, unless otherwise indicated.

\title{
Psychosocial development in youth soccer players: assessing the effectiveness of the 5C's intervention program
}

PLEASE CITE THE PUBLISHED VERSION

http://dx.doi.org/10.1123/tsp.2014-0161

\section{PUBLISHER}

(c) Human Kinetics as accepted for publication

\section{VERSION}

AM (Accepted Manuscript)

\section{PUBLISHER STATEMENT}

This work is made available according to the conditions of the Creative Commons Attribution-NonCommercialNoDerivatives 4.0 International (CC BY-NC-ND 4.0) licence. Full details of this licence are available at: https://creativecommons.org/licenses/by-nc-nd/4.0/

\section{LICENCE}

CC BY-NC-ND 4.0

\section{REPOSITORY RECORD}

Harwood, Chris G., Jamie Barker, and R. Anderson. 2019. "Psychosocial Development in Youth Soccer Players: Assessing the Effectiveness of the 5c's Intervention Program". figshare. https://hdl.handle.net/2134/19038. 
Psychosocial development in youth soccer players: Assessing the effectiveness of the 5C’s intervention program

Running head: Psychosocial development in youth soccer

Keywords: coaching, youth soccer, psychosocial, single-case design, case study 
Abstract

2 This study examined the effectiveness of a longitudinal 5C coaching intervention

3 (Harwood, 2008), focused on promoting behavioral responses associated with

4 commitment, communication, concentration, control, and confidence in youth soccer

5 players. Five players, their parents and a youth academy soccer coach participated in a

6 single-case multiple-baseline across individuals design with multiple treatments.

7 Following baseline, the coach received sequential education in the principles of each

8 'C' subsequent to integrating relevant strategies in their coaching sessions. During the

9 five intervention phases, players completed assessments of their behavior in training

10 associated with each $\mathrm{C}$, triangulated with observation-based assessments by the coach

11 and the players' parents. Results indicated psychosocial improvements with

12 cumulative increases in positive psychosocial responses across the intervention for

13 selected players. Changes in player behavior were also corroborated by parent and

14 coach data in conjunction with post-intervention social validation. Findings are

15 discussed with respect to the processes engaged in the intervention, and the

16 implications for practitioners and applied researchers. 
Psychosocial development in talented youth soccer players: Examining the effectiveness of the 5C's intervention program

The last decade of sport psychology research has been marked by a surge in interest related to positive developmental outcomes in young athletes. Investigations focused on the psychosocial processes of talent development and psychological characteristics of elite youth athletes (e.g., Holland, Woodcock, Cumming, \& Duda, 2010; MacNamara, Button, \& Collins, 2010a,b) lie adjacent to studies targeting positive youth development (PYD) and life skills through sport (Camiré, Forneris, Trudel, \& Bernard, 2011; Strachan, Côté, \& Deakin, 2011; Gould \& Carson, 2010; Jones \& Lavallee, 2009). In many respects, the differences between these sub-fields of pediatric sport psychology rest in consideration of their end goals. For some researchers, PYD through sport and the development of life skills are the end objectives (e.g., Camiré et al); whereas for others, the end point is how specific psychological skills and strategies influence performance and talent transition (MacNamara et al., 2010a). Both avenues of research matter in the modern-day commercial and social contexts of sport and health, yet it is important to acknowledge that the vast majority of young athletes in competitive sport programs will not transition to elite level. This fact necessitates both a coach's and sport organization's attention towards the issue of how to maximize developmental experiences and outcomes for all protégés, whilst maintaining a balanced focus on qualities most associated with performance improvement (see Johnston, Harwood, \& Minniti, 2013; Vella, Oades, \& Crowe, 2011). Harwood's (2008) applied research and consulting experience in an English professional youth soccer academy was representative of this specific contextual need to integrate attention to psychosocial skill development in youth players. In his study, 
1 he noted limited intentional work by coaches on developing players’ psychological

2 and social skills, yet schoolboys as young as eight years of age faced the pressure of

3 retaining their place in the academy on a yearly basis. Harwood's approach

4 championed the role of organized youth sport programs built on producing mentally

5 healthier, more psychosocially competent individuals, rather than simply skilled

6 performers (Côté \& Fraser-Thomas, 2007; Danish, Hodge, Heke, \& Taylor, 2003;

7 Fraser-Thomas, Côté, \& Deakin, 2005; Gould, Flett \& Lauer, 2012; Lerner, Fisher, \&

8 Weinberg, 2000). In formulating the processes of his intervention work, he drew on

$9 \quad$ Fraser-Thomas and colleagues notion of an applied sport-programming model based

10 on Bronfenbrenner's (1999) bio-ecological model of youth development. Fraser-

11 Thomas et al. contended that youth development occurs within a dynamic

12 environment that promotes key internal assets (e.g., commitment to learning;

13 interpersonal competence; restraint and self-esteem); and, most importantly, that the

14 regularity and quality of reciprocal social relationships experienced by players

15 working with coaches, parents and peers (i.e., external assets) are integral to

16 developmental outcomes. Academy youth soccer presents an ecological microsystem

17 (Bronfenbrenner, 1999) within which coach, player and teammate-peers interact

18 intensively (i.e., up to four times per week) throughout a season. In addition, Harwood

19 also noted the impact of Smith and Smoll's (1997) Coaching Effectiveness Training

20 (CET) program as a vehicle for optimising an athlete's psychosocial experience

21 through coaching behavior education.

In the general PYD literature, Lerner et al. (2000) referred to the 6 C's of

23 youth development: competence, character, connection, confidence, caring and

24 ultimately, contributions. These qualities reflected the desired outcomes within their

25 Model of National Youth Policy towards the development of a civilized society. In 
1 taking a more sport-specific approach, Harwood (2008) coined his intervention

2 framework 'The 5C's', incorporating a focus on behaviors associated with

3 commitment, communication, concentration, control, and confidence. These terms

4 were deemed to be user friendly for players, coaches and parents in soccer, yet

5 represented the key motivational, self-regulatory and interpersonal attributes that

6 typically formed the core of educational interventions in youth sport (e.g., Thelwell,

7 Greenlees, \& Weston, 2006; Vealey, 1988). Importantly, given an emphasis on

8 fostering youth development through sport, such constructs also reflected internal

9 assets from PYD (Benson, 1997) and shared similarities with the psychosocial

10 competencies viewed as important for successful talent transition in youth soccer

11 (Holt \& Dunn, 2004).

Although Harwood (2008) described his educational work with parents and

13 players, his main field-based intervention with the 5C's focused on increasing

14 coaching efficacy through the use of a supervisory consulting approach (Smith \&

15 Johnson, 1990). Specifically, he observed the lack of confidence that coaches

16 possessed in integrating psychological themes into their practices (see Gould,

17 Darmijian, \& Medbery,1999) and sought to influence this by delivering a longitudinal

18 coach education initiative. The format of the 5C's coaching efficacy intervention

19 incorporated cycles of awareness and education, application, and evaluation. Coaches

20 were introduced to each ' $C$ ' in separate 90 minute workshops where awareness was

21 raised around core theoretical principles and practical applications associated with

22 that specific psychosocial construct. Influenced by the application of social cognitive

23 theories in past intervention research (e.g., Harwood \& Swain, 2002; Smith \& Smoll,

24 1997), Harwood (2008) drew upon achievement goal theory (AGT; Nicholls, 1989),

25 self-determination theory (SDT; Deci \& Ryan, 2005), attention control training 
1 (Nideffer \& Sharpe, 1978) and self-efficacy theory (Bandura, 1977) to inform his

2 work with coaches. Each workshop involved coach-led discussion of the coaching

3 strategies and interactions that would help the player to demonstrate and develop the

4 player behaviors that coaches agreed were associated with each C. Following each

5 workshop, coaches then practiced the application of these coaching strategies in their

6 normal training sessions with players. After five sessions, coaches' levels of efficacy

7 were reassessed prior to commencing the educational workshop on the next C. This

8 cycle of education-application-evaluation continued until the principles, practices and

9 behaviors associated with commitment, communication, concentration, control and

10 confidence had been covered.

11 Applying features of a single-case, multiple baseline design with multiple

12 treatment phases to four coaches (see Barker, McCarthy, Jones, \& Moran, 2011),

13 Harwood's (2008) intervention demonstrated positive increases in coaching efficacy

14 with the 'communication' coaching phase being particularly effective on the

15 confidence of coaches. Coaches also reported on the psychosocial behaviors of their

16 squad of players throughout the intervention, and noted squad improvements in each

17 C, corroborated further by social validation data.

18 Despite promising efficacy perceptions and interpretations of impact from

19 coaches in their role as external assets to player development (Benson, 1997; Fraser-

20 Thomas et al., 2005), there were several key limitations to Harwood’s (2008) initial

21 investigation. First the lack of an appropriate stable baseline period was an

22 acknowledged methodological weakness in the single-case approach used. Pre-

23 intervention assessments were taken only once prior to the commencement of

24 educational workshops. In single-case research at least three distinct data collection

25 points are advised to establish baseline stability in the dependent variable(s) prior to 
1 intervention (Barker et al., 2011). Second, no data was collected from the players

2 themselves, and even though the intervention was targeted at improving coaching

3 efficacy, the primary intention of such initiatives is ultimately the psychosocial

4 development of the young player. On this point, a number of intervention studies

5 have shown that training programs can improve psychological strategies among

6 young athletes (e.g., Fournier, Camels, Durand-Bush, \& Salmela, 2005; Martin \&

7 Toogood, 1997; Sheard \& Golby, 2006). Such programs have taught one strategy to

8 enhance a certain characteristic (e.g., self-talk; Johnson, Hrycaiko, Johnson, \& Halas,

9 2004) or multiple strategies to enhance a range of psychological skills (Fournier et al.;

10 Mamassis \& Doganis, 2004; Sheard \& Golby, 2006). In all of these studies, data were

11 collected from the athletes; however no study specifically used the coach as the

12 intervention instrument for athlete psychosocial development as in Harwood's 13 approach.

14 Given the aforementioned points, the purpose of this current study was to

15 explore the effectiveness of the 5C's coach education program more directly on the

16 psychosocial behavior of youth players in an English soccer academy. As youth

17 players manage an important talent transition phase at 12 years of age within the

18 English soccer structure (being contractually signed for a two year period in the Youth

19 Development Phase (Football Association, 2010), players from the Under-13 age

20 group were the focus of this investigation. In addition to data collected from each

21 participant player, observation-based assessments by the coach and the players'

22 parents served as sources of data triangulation to explore the effectiveness of the

23 intervention. Based on the initial research in soccer (Harwood, 2008), we posited that

24 players would report improved psychosocial responses (i.e., each of the 5Cs) between

25 baseline and post-intervention phases. In addition, reported improvements in a 
1 specific psychosocial construct (e.g., communication) would be associated with the

2 introduction of the coaching intervention (i.e., treatment phase) related to that specific

3 construct (e.g., communication coaching phase; control coaching phase). Continual

4 assessments by coach and parents were also employed to evaluate the effectiveness of

5 the intervention alongside player data.

\section{Method}

\section{Participants}

The participants were players from the Under-13 age group squad at a

9 professional soccer club academy in the United Kingdom. The inclusion criteria for

10 the project were that (a) the player had been signed for the year at the academy, (b)

11 the player, and a parent (as observer) were in regular attendance at the training

12 sessions, and, (c) the players were outfield players, given that the academy provided

13 separate, simultaneous goalkeeping training. As a consequence, out of 16 players in

14 the squad, five players $(M=12.58$ years, $\mathrm{SD}=.23)$ were eligible to participate in the

15 data collection. These players covered all outfield positions of defenders (two

16 participants), midfielders (two participants) and striker (one participant). The lead coach was 38 years old, holding a high level coaching award (UEFA 'B' level) with 10 years coaching experience. He had little prior training or academic background in sport psychology; his formal knowledge of the discipline being limited to discrete group education seminars within his prior coaching awards. Each of player's parents

21 who agreed to be involved in the study were male $(M=45.9$ years, SD $=7.17)$, and

22 consented for their child's participation. Ethical clearance was provided by the first

23 author's institutional ethics committee, and informed consent was received from all 24 participants before proceeding with data collection. 


\section{Intervention Design}

A single-subject multiple baseline across individuals, with multiple treatments was used (Barker et al., 2011; Martin \& Pear, 2003). The introduction of the intervention typically takes place when a stable baseline of the dependent variable is achieved, or performance moves in a direction opposite to that expected following treatment (Hrycaiko \& Martin, 1996). Because the study incorporated multiple dependent variables (i.e., 5C's), an 'a priori’ decision was taken to set the baseline period to three weeks, and set the intervention period for each psychosocial construct (C) to three weeks, based on the number of weeks remaining during the season (eighteen). A similar research approach has previously been implemented in other studies of a similar, seasonal nature without detriment to data collection (e.g., Thelwell et al., 2006). In addition, characteristic to single case research designs and supportive of a mixed method approach, post-intervention social validation data was collected from participants to understand their experience of the project and perceptions of intervention delivery (Barker et al., 2011).

\section{Instrumentation}

Assessment of Psychosocial Responses. Based on Harwood’s (2008) specific measure of the 5C's, a post-training session questionnaire was developed in the current study to assess the psychosocial responses and behavior of players in each training session. The 15 items (three behaviors per C) were subject to further content validation in order to optimize the ecological validity for this specific study. Content validation process. A separate sample of six youth soccer players ( $M$ $=11.2$ years, $\mathrm{SD}=.26)$ and six UEFA A and B licensed youth soccer coaches $(M=$ 44.6 years, $\mathrm{SD}=7.39$ ) were recruited for this additional process of content validation. They evaluated each item in relation to: (a) the 5C psychosocial construct to which it 
1 belonged; and (b) the overall clarity of the item and its ease of understanding as a

2 psychosocial behavior. A seven point Likert scale ranging from 'Not at all

3 clear/difficult to understand' (1) to 'Very clear/easy to understand' (7) was applied for

4 the latter assessment with participants invited to make comments with reference to

5 further clarity. All of the items were deemed as clear yielding mean responses of

6 above five across all participant groups. The coaches correctly matched the item

7 statement with the appropriate C. However, two of the six players placed one of the

8 'Confidence' statements (i.e., always wanted the ball and didn't hide away if things

9 were going wrong) in a 'Commitment' category, and one of the 'Concentration'

10 statements (i.e., listening to the coach and maintaining eye contact) in the

11 'Communication' category. However, given the majority of positive responses across 12 both groups, and particularly the verification by adult coaches, the questionnaire was 13 subjected to only minor word changes.

5C post-training questionnaires. The players, the coach and parents

completed versions of the final 15-item questionnaire after each training session during baseline and intervention phases. The stem was adapted for each group of respondents, with the coach and parents being asked "How much would you say you witnessed the following types of behaviors and responses in this player/your son in the previous training session?" The players were asked to consider "How much do you think that you showed the following behaviors and responses in the last training session?”. Respondents were prompted to answer on a 7-point scale (1= strongly disagree, $4=$ neither agree/disagree, $7=$ strongly agree) to each of the 15 statements including: "tackled challenges and difficult drills/exercises consistently throughout the session” (commitment), "praised teammates when they encouraged \& listened to others"(communication), "listened to instructions carefully and kept eye contact with 
1 the coach" (concentration), ), "stayed positive after mistakes" (control) and "always

2 wanted the ball and didn't hide away if things were going wrong” (confidence).

3 Aligned with Harwood's (2008) intervention, all participants were blind to the 5C

4 structure of the questionnaire that was simply entitled the 'Soccer Training Review'.

5 The internal consistency scores using Cronbach's alpha coefficient across the

6 intervention for the participants, in relation to commitment (.83), communication

7 (.92), concentration (.81), control (.86) and confidence (.75) all exceeded the criteria

8 value of .70 .

\section{Procedure}

The baseline data collection and intervention structure was based on the

11 protocol described and conducted by Harwood (2008).

Initial meeting and baseline phase. Following an individual meeting with

13 the coach, separate meetings were held with each of the five players and their fathers

14 where informed consent was obtained. Participants were informed that the study was

15 about players' experiences in training sessions and to gain player and parental

16 perceptions of training across the season. Instructions were given to complete the

17 'Soccer Training Review' separately within 24 hours of the last training session, and

18 the importance of reviewing the session independently was reiterated to maximize

19 honest, individual perceptions. The coach was asked to complete a 'Soccer Training

20 Review' on each of the five participant players for the two scheduled sessions per

21 week. The next three weeks of training (i.e., a maximum of six sessions) were

22 targeted as the baseline phase of the study.

23 The intervention phase: 5C coach education. Preliminary analysis of the

24 player data from the 5C questionnaire indicated a set of stable baseline 5C responses

25 during the first three weeks of training. Therefore, the intervention phase commenced 
1 with the first of five personal coach education sessions aimed at introducing each of

2 the 5Cs. The first session extended to 75-minutes and began by raising awareness of

3 the importance of sport psychology and the important role of the coach in facilitating

4 the psychosocial development of players. This allowed the overall concept of the 5Cs

5 to be presented to the coach, before narrowing attention to the first $\mathrm{C}$ - Commitment -

6 that would serve as the main focus for the session. Based on Harwood's (2008)

7 protocol for group coach education, each of the 5C coaching sessions included:

8 awareness and discussion of behaviors linked to each C; presentation of principles or

9 theoretical underpinnings for each C (e.g., the Commitment coaching phase focused

10 on the principles of AGT [Elliot, 1999; Nicholls, 1989] and SDT [Deci \& Ryan,

11 1985]); and discussion of coaching behaviors, drills and management strategies to

12 influence each C (e.g., the creation of a task involving and autonomy supportive

13 coaching climate). As presented in Harwood (2008), the coach was introduced to

14 eight coaching behavior guidelines (see Table 1) that encouraged the development of 15 an optimal learning environment for all coaching sessions in the intervention. These

16 session management and behavioral strategies were relevant to incorporate in

17 coaching segments at the start of a session (i.e., pre-briefing), throughout the session,

18 and at the end of the session (i.e., debriefing) to gain maximum attention from, and

19 impact on, players with respect to each C (see Harwood \& Anderson, 2015). At the

20 end of this first education session, the coach was provided with a 5C coaching session

21 action plan sheet to support him in the ongoing development of his 5C approach.

22 Following this education, the coach was tasked with integrating 'Commitment

23 coaching' strategies into his normal soccer academy sessions so that there was

24 minimal deviation away from the technical curriculum operated by the professional

25 academy. This first treatment phase lasted for three weeks (i.e., up to six sessions) 
1 during which the coach, players and parents completed their 'Soccer Training

2 Review'. Players and parents were unaware of the progressive coach education

3 process and that the coach was purposefully attending to the first ' $\mathrm{C}$ ' - Commitment

4 (and subsequent C's) in his sessions as part of the research program.

5 The second treatment phase began following the second coach education

6 session scheduled three weeks later. This session targeted Communication and

7 followed the same approach as identified previously. The coach paid attention to these

8 strategies in the next three weeks of training, and so the process continued every three

9 weeks until all 5Cs had been educated and implemented. Therefore, treatment phases

10 three, four and five were represented by Concentration coaching, Control coaching

11 and Confidence coaching strategies respectively. Each of these latter coach education 12 sessions lasted approximately 50 minutes.

Post-intervention social validation. A post intervention social validation

14 form for each player, parent, and the coach was used to explore the processes

15 associated with the intervention and its effects (Barker, Mellalieu, McCarthy, Jones,

16 \& Moran, 2013; Page \& Thelwell, 2013). The questionnaire provided parents and

17 players with greater information about the nature of the study, and allowed for open-

18 extended answers to be given based on: satisfaction with the outcomes of the

19 intervention; perceived improvements in 5C's use based on the psychology-related

20 coaching skills implemented; reflections on the delivery of sessions (coach) and being

21 coached (players); levels of skill transfer to matches; and whether there were any

22 experienced problems or difficulties with the program. Space was also made available

23 to openly comment on any other issues or observations deemed relevant. 
1 Procedural Reliabilty

To ensure that each participant was treated equally, post intervention scores

3 were not viewed until all participants had completed the entire data program. Further,

4 the pre-determined and structured nature of the intervention protocol ensured

5 consistency of delivery across all participants (Barker et al., 2013).

6 Data Analysis

A combination of visual and graphical analysis was used to examine the

8 effectiveness of the intervention on the players, and the perceptions of coach and

9 parents (Barker et al., 2013). Examination of data took place for each dependent

10 variable (i.e., each C) using a combination of graphs and descriptive statistics. To

11 illustrate, intervention effects for the players were analysed using both descriptive

12 statistics (e.g., visual comparison of mean values and percentage change from

13 baseline to the presentation of the specific $\mathrm{C}$ intervention phase) and graphs, whilst

14 descriptive statistics from the coach and parents were explored across the study to

15 corroborate change patterns. Player treatment effects were determined from visual and

16 graphical analysis when: (a) baseline performance was stable or in a direction

17 opposite to that predicted for the treatment, (b) the fewer the number of overlapping

18 data points between baseline and treatment phases, (c) the sooner the effect occurs

19 following the introduction of the treatment, and (d) the larger the size of the effect in

20 comparison to baseline (Hrycaiko \& Martin, 1996). In addition, supporting the mixed

21 methods adopted in this study, key insights from the social validation phase post

22 intervention are also presented.

\section{Results}

24 The results of this study are organised into three sub-sections. First, we introduce the 25 group-based analyses of descriptive data collected for players, coach, and parents 
1 across the length of the study. Second, we provide a more in depth, idiographic

2 analysis for each of the players. Finally, we focus on the social validation data and

3 attend to the participants experiences of the intervention.

Overall, visual comparison of the mean levels from baseline to post-

5 intervention for the dependent variables indicated players' perceptions of their 5C

6 psychosocial responses and behaviors increased following the 5C intervention (see

7 Table 2). Moreover, visual inspection of the change in means and percentage

8 difference from the total baseline score for each $\mathrm{C}$ to the end of its specific treatment

9 phase revealed increases across all of the Cs for the players. Triangulated data from

10 the coach and parents of the player's revealed similar perceptions of psychosocial

11 response progressions (see Table 3). Finally, consideration of cumulative changes in

12 overall psychosocial responses (i.e., mean across all of the 5Cs) at baseline time 3 to

13 time 8 (i.e., the end of the study), further supported changes in perceptions of 5C

14 development across all players. Table 4 illustrates how these changes are corroborated

15 by the perceptions of the coach and parents.

\section{Player 1 (Striker)}

Player 1, occupying a forward position as a striker in the team, reported low

18 levels of communication, with moderate levels of commitment and control, and

19 moderate-to-high levels of concentration and confidence-related behavior prior to the

20 intervention. Following treatment phase 1 of the intervention there was an immediate

21 increase in perceptions of all of the Cs with the exception of confidence which

22 remained stable. Across the study, player 1 demonstrated no overlapping data points

23 (Figure 1). Extraction of data taken prior to and during the specific C-related

24 treatment phase indicated a number of positive changes for this player across the

25 study. Specifically, during the commitment-coaching phase, perceptions of 
1 commitment-related behavior notably increased (4.33 > 5.78). In addition, there was

2 a noticeable elevation in perceptions of communication $(3.50>4.39)$. By the end of

3 the communication-coaching phase that followed, player 1's reported communication

4 had improved to an increased level $(4.39>5.89)$. After the concentration phase an

5 immediate change in attention-related behavior was reported $(5.61>6.00)$, whilst

6 skills associated with emotional control were perceived to be greater following the

7 control phase $(4.78>5.94)$. The confidence coaching phase promoted a further

8 change in confidence perceptions $(6.00>6.39)$ in spite of a gradual rise throughout

9 the other intervention phases. In sum, across the coaching intervention phases, player

101 experienced positive effects in their 5Cs. Only behaviors associated with emotional

11 control remained stable until the onset of the specific control coaching phase that

12 subsequently influenced these behaviors.

13 Player 2 (Central Defender)

14 Player 2, a central defender in the team, commenced the intervention with

15 moderate perceptions of training behaviors related to commitment, communication,

16 concentration and confidence, and a low perception of his control-related behavior.

17 Following treatment phase 1 of the intervention there was an immediate increase in

18 perceptions of all of the Cs. Across the study, player 2 displayed no overlapping data

19 points (Figure 2). Extraction of data taken prior to and during the specific C-related

20 treatment phase indicated a number of intervention effects. After the commitment-

21 coaching phase, a substantial increase occurred in commitment $(4.50>6.39)$,

22 however increases for the remaining Cs were also perceived during this phase. The

23 communication-coaching phase produced substantial reported increases in

24 communication $(4.89>6.06)$, as well as minor positive or maintenance effects in the

25 remaining Cs. The elevated levels of control and confidence reported following the 
1 two prior phases were not retained during the concentration-coaching phase, though

2 they still remained considerably higher than pre-intervention levels. Importantly

3 during this phase, concentration perceptions changed positively $(5.50>6.22)$.

4 Reported levels of control-related behavior $(4.78>5.99)$ increased during the control

5 intervention phase, whilst the other Cs remained stable. Finally, following the

6 confidence-coaching phase, player 2 reported a change in concentration $(6.33>6.78)$,

7 control $(5.89>6.50)$ and confidence $(6.06>6.67)$, whilst his improved levels of

8 commitment and communication remained stable.

\section{$9 \quad$ Player 3 (Left Midfielder)}

Player 3, occupying a left midfield position in the team, reported moderate

11 pre-intervention levels for all of the 5Cs, however as with players 1 and 2, he reported

12 an immediate increase in perceptions of these psychosocial behaviors following

13 treatment phase 1 - the commitment-coaching phase. Across the study, player 3

14 displayed no overlapping data points (Figure 3). Extraction of data taken prior to and

15 during the specific C-related treatment phase indicated a number of positive effects.

16 Specifically, reported levels of communication increased progressively throughout

17 each phase, but an improvement is noticeable during the communication-coaching

18 phase. Levels of concentration were reported to improve following the concentration-

19 coaching phase, but continued to increase throughout each of the remaining

20 intervention phases $(5.78>6.56)$. Player 3's control-related behavior remained stable

21 during the prior two phases before responding markedly $(4.67>6.17)$ to the control-

22 coaching and confidence coaching phases. Finally, following a small decrease in the

23 concentration phase, player 3's confidence increased from the control-coaching phase

24 through to the confidence intervention phase $(5.89>6.39)$. In sum, whenever player

253 entered a new coaching intervention phase focused on a specific C, he reported 
1 improvements in his experience and application of behaviors associated with that

2 psychosocial attribute.

3 Player 4 (Central Midfielder)

Player 4 was a central midfielder in the team and commenced the study with

5 moderate pre-intervention levels for all of the 5Cs, except for more elevated levels of

6 confidence. Across the study, player 4 displayed one overlapping data point (with

7 week 1 of the baseline) for control, along with some illustration of a decreasing

8 baseline for commitment, confidence, and control. Following the pattern of other

9 players, he reported an immediate increase in perceptions of these psychosocial

10 behaviors following treatment phase 1 - the commitment-coaching phase (Figure 4).

11 Extraction of data taken prior to and during the specific C-related treatment phase

12 indicated a number of positive intervention effects. For example, whilst impacting on

13 the other 4C's, the commitment-coaching phase appeared to have a substantial effect

14 on player 4's motivation-related behaviors $(4.00>6.06)$. Following this initial

15 coaching phase, his reported levels of commitment remained stable until further

16 improvement during the confidence coaching phase. Player 4's modest levels of

17 reported control were gradually decreasing during the communication and

18 concentration coaching phases, until the onset of the control coach education and

19 intervention phase (see Figure 4). Over these next three weeks, there were notable

20 improvements in this player's control-related behavior a result of control coaching

21 (4.61 > 5.78). Furthermore, the confidence coaching phase resulted in slightly

22 improved levels of all 5C responses as a follow-on from the control coaching phase.

\section{Player 5 (Right Back)}

24 Beginning with modest pre-intervention scores, each intervention phase was

25 largely associated with increases in each of the 5Cs for player 5, and he displayed no 
1 overlapping data points (Figure 5). Extraction of data taken prior to and during the

2 specific C-related treatment phase indicated a number of intervention effects. First,

3 he reported increases in commitment $(4.67>5.83)$ and confidence $(4.00>5.22)$

4 following the commitment coaching phase. These increases were followed with

5 further reported changes in commitment $(5.83>6.22)$ and communication $(5.06>$

6 6.28) following the communication intervention phase. These psychosocial responses

7 were largely retained during the concentration phase, with the exception of slightly

8 improved concentration (5.33 > 5.78). Player 5 reported elevated levels of control-

9 related behavior $(4.39>5.67)$ during the control-coaching intervention, a phase where

10 further improvements were noted in the other Cs. Mirroring player 4, the confidence

11 coaching phase also appeared to produce further linear improvements in player 5's

12 psychosocial responses.

13 Social Validation

14 Several insights into the delivery and benefits of the intervention emerged

15 through social validation. All players expressed an increase in the knowledge and use

16 of the psychological skills and behaviours related to the 5Cs as a result of the

17 coaching intervention. Player 3 commented:

“I think I am better now doing the 5Cs because of the training we did. My coach wanted me to dribble a lot more but I did not want to get tackled. I am confident now that I can dribble past people and not get tackled, and when I dribble past someone I know I need to look where my strikers are and where the defenders are to have a good end product, so we can score.”

23 This player's perception of his improved confidence and concentration was validated

24 by his father who noted: 
“I saw a definite improvement in my sons' use of the 5Cs. He was working harder, talking more and seemed able to concentrate better in training and matches. He looked more prepared to try new things without the fear of making mistakes.” (Parent 3)

The coach also articulated the positive effects of an increased knowledge of psychology for his coaching, and how the systematic approach aided confidence in his delivery:

“I’ve never been taught psychology before and always thought it was just about getting one over on your opponent. My knowledge of the 5Cs was very limited. I've definitely improved as a coach because of the 5Cs. Its simplistic structure helped me get the message across and for the kids to understand it.”

One of the parents (parent 1) echoed the importance of psychology and the role of the coach in helping his players:

"Psychology is growing in football and so it is important to teach it to players so they can deal with the high pressure demands of the game. The 5Cs stuff that the coach did seemed very good in doing that.”

The transfer of skills as a result of the intervention was a further theme in player and parent responses. In essence, there was perceived transfer of skills from training to matches. Player 1 commented:

"I am talking a lot more to my team mates around me and being positive to them. I am also playing with a lot more confidence now and any mistakes I make in a game or at training don't worry me. I just get over it and carry on playing.” 
1 Moreover, several parents noted a translation of skills taught during soccer training to

2 their sons' school work. For example with reference to communication, Parent 4

3 wrote:

"I've noticed over the last 3 or 4 months that the grades my son has been getting in his English presentations have got better. He always used to hate speaking in front of people and now he seems more comfortable with it.”

Parent 5 supplemented this by noting:

"It always used to be a struggle to get him to do his homework, but now it’s rarely a problem. He even once told me that he was 'committed' to getting it done before dinner!”

The coach began every session with a pre-briefing, during which one of the 5C's was introduced and the players were given a short task to undertake prior to starting the session. Player 5 acknowledged how enjoyable the players found this exercise: "The games before training were really fun. We always wanted to make sure we were there on time. I missed them a couple of times because I was late and I missed out. They were a fun way to learn about the $C$ that we were doing in that training and I really enjoyed them.”

In addition, the coach used rotating 'peer monitors' during his sessions giving each player the responsibility to feedback to the squad on how players were doing in the performance of a specific ' $\mathrm{C}$ '. This peer strategy aided the levels of focus on a specific psychosocial attribute, as Player 4 affirmed: “The monitors were good because they made us not drop how well we were doing, or do better when we weren't training well. Everyone got a go as well which was good”. From the onset of the intervention, Parent 4 commented on how he saw improvements from the commitment-coaching phase: 
"You could tell straight away, watching the sessions, when the coach set the players a challenge, they all were more motivated to achieve throughout the whole session. The player's commitment increased dramatically. I remember asking my son about it and being told it was about setting a goal against yourself to improve. I think it explains the higher tempo and quality to the sessions when this was used.”

Nevertheless, across the majority of players, their parents and the coach, the greatest advances were perceived to lie with communication training. Teammates were noted to help each other by providing support and encouragement, modeling and instilling helpful behaviors that impacted on overall experience of training. Player 2 expressed the following:

"I really enjoyed the communication stuff we did. I get told a lot to communicate but I never knew what to say. Now I do! I even got into competitions with [another player] to see who could be the loudest and most helpful during training and matches to help us do better.”

Such perceived communication changes were also noticed by the parents who attributed large improvements in performance to the cooperation and maturity demonstrated between the players. Finally, all the players commented on how they were encouraged to continue using the $5 \mathrm{C}$ strategies and behaviours from previous phases within the current phase that was being coached.

\section{Discussion}

The purpose of the current study was to contribute to the extant literature by extending previous work surrounding the 5Cs (see Harwood, 2008) and to explore the effectiveness of a longitudinal 5Cs coaching intervention at enhancing youth soccer players' psychosocial responses and behaviors in training. Motivated by both talent 
1 and positive youth development agendas, the intervention was based on the belief that

2 psychological assets and interpersonal competencies in young people can be shaped

3 by significant others in a structured, supportive environment (Benson, 1997; Fraser-

4 Thomas et al., 2005; MacNamara, Button, \& Collins, 2010b; Petitpas, Cornelius, Van

5 Raalte, \& Jones, 2005). In this regard, the coach plays the role of a key external asset

6 who is optimally placed to create an environment where effective role models,

7 positive reinforcement and supportive peer influence can assist in the learning and

8 development of the young player (see Smith \& Smoll, 1997). As such, the current

9 research adopted Harwood's (2008) coach education initiative to assist an individual

10 coach in bringing a more focused psychosocial dimension to his role with adolescent

11 youth academy players.

Overall, the findings provide initial support for the effectiveness of delivering

13 an interactive series of educational workshops that systematically focused on relevant

14 psychosocial attributes (Holt \& Dunn, 2004; Thelwell et al., 2006). Several aspects of

15 these results warrant discussion in the context of their contribution to the processes

16 that may facilitate the psychological growth of adolescent athletes in elite sport

17 settings.

To illustrate, the introduction of the first coaching phase focused on

19 stimulating commitment behavior was associated with immediate increases in the

20 majority of psychosocial responses reported by all players. A similar finding was

21 reported by Harwood (2008) who proposed that the coaches' attention to creating a

22 mastery climate (Smith, Smoll, \& Cumming, 2007), with a particular focus on player

23 effort, persistence and self-improvement with peer support, may serve as ingredients

24 to encourage communication, concentration, self-control and expressions of

25 confidence in players. Further, third-party observations by parents provided some 
1 validation for the initial impact of the commitment coaching phase. Compared to

2 Harwood, the present study benefited from a stronger methodological design in that

3 an extended baseline was established pre-intervention and the 5C psychosocial

4 responses were reported by individual players themselves as opposed to the coaches'

5 perceptions of their entire squad's behavior in training (Barker et al., 2013).

6 Progression through the four subsequent coaching phases supported the

7 influence of the coach's strategic behavior on phase-relevant psychosocial responses

8 (Camiré et al., 2011). The communication coaching phase was associated with further

9 reported increases in interpersonal behavior for all players, including selective

10 increases in commitment, control and confidence-related responses for three of the

11 five players. Post-intervention social validation data by players, coach and parents

12 supported the data depicting how communication-related behavior was the most

13 improved of all the 5C's in general (see Table 2 and 3). Data also illustrated how

14 several players retained moderately improved levels of concentration and control

15 before more acute positive responses were reported when the coach focused

16 specifically on these qualities for each three week period. The final confidence

17 coaching phase in which the coach encouraged players to share their progressive

18 accomplishments, acknowledge teammates' skill improvements, and act confidently

19 when taking on new challenges was again associated with continued increases in the

20 motivational, interpersonal, attentional and emotion-regulatory responses of the

21 players.

22 These findings offer some initial and encouraging support for the principles

23 and processes of the 5C coach education sessions and subsequent coaching

24 intervention strategies. Qualitative social validation data reinforced the improvement

25 in knowledge gained by the coach and players, as well as the benefit of pre-session 
1 awareness tasks, in-session peer feedback and 5C review strategies employed by the

2 coach in training (Camiré et al., 2011). These strategies illustrate the salience of

3 applying the eight coaching guidelines proposed by Harwood (2008) and the utility of

4 the 5C training session preparation and planning sheet for the coach.

In sum, from a mechanistic perspective, the findings serve to reinforce the

6 ecological approach to youth development (Bronfenbrenner, 1999) where coaches represent significant figures in a young athlete's microsystem; and where intensive coach-player and peer contact (e.g., up to four times per week) may exert an influence

9 on player behavior through the creation of an optimal social learning environment.

10 Such an environment was initiated in this instance by collaboratively raising

11 awareness in the coach of the key principles and practices of leading theories pertinent 12 to psychosocial development in sport (e.g., Bandura, 1997; Deci \& Ryan, 1985;

13 Nicholls, 1989). Subsequently, we believe that the creation of a psychosocial

14 coaching climate, built on the principles of AGT, SDT and self-efficacy theory,

15 helped to operationalize stronger youth development practice in the soccer setting.

16 For sport psychology practitioners working with youth teams, the results of this study indicate the potential value of considering the coach as an integrated ally and conduit for the psychological development of young athletes. Indeed, coaches who are motivated to learn about optimising their psychological role may benefit greatly from this youth-based form of the supervisory consulting model (Smith \&

21 Johnson, 1990). To illustrate, Pain and Harwood (2004) identified that time,

22 knowledge and awareness on behalf of coaches served as barriers to the successful

23 implementation of sport psychology programs in English soccer academies. Perhaps

24 by integrating a focus on psychosocial skills more seamlessly into a soccer academy’s

25 coaching syllabus, coaches may become more knowledgeable, confident and 
1 supportive of the wider and more specialized role that psychology can play in talent

2 and positive youth development (Camiré et al., 2011; Côté \& Fraser-Thomas, 2007;

3 Gould et al., 2012; Vella et al., 2011).

4 Strengths, limitations and future directions

By building upon the initial work and suggestions of Harwood (2008), the

6 study aimed to incorporate further methodological strengths beyond the use of an

7 improved single-case design (Barker et al., 2013). The data reported by coaches and

8 parents, all fathers in this case, served to triangulate the assessment of the

9 effectiveness of the coach education program. Their data corroborated the experiences

10 and findings of the players when examining the changes in psychosocial responses

11 from several different vantage points pre and post intervention. In sum, the coach and

12 parents indicated that players were demonstrating a range of consistently positive

13 behaviors in training compared to the baseline phase earlier in the season.

14 In support of parental observations made in Harwood's (2008) study, the

15 parents involved in this study offered further perceptions on transferable skills.

16 Parents commented on how the program impacted on domains beyond soccer, namely

17 their son's motivation for schoolwork or confidence in giving academic presentations

18 (Gould \& Carson, 2010). Despite the widespread belief that sport participation teaches

19 life skills, evidence suggests that life skills do not transfer automatically from one

20 domain to another (Danish, Taylor, Hodge \& Heke, 2004) and that specific strategic

21 approaches are required to promote such transferability (see Camiré et al., 2011).

22 Whilst the current study attempted to represent itself as an innovative field-

23 based intervention that rationally extended past work, there are several critical

24 reflections, limitations and future directions to consider. First, this investigation is

25 based entirely on subjective as opposed to objective data. Even though the perceptions 
1 of coach and parents serve to validate the self-report data from players, the findings

2 are not immune from a socially-desirable response bias. The visual improvements

3 across the multiple baselines (i.e., all players) with very limited overlapping data

4 support positive intervention effects. However, it was impossible given the nature of

5 the study to stagger the intervention phases for each separate player, and this must be

6 acknowledged as a threat to the external validity of the findings (see Barker et al., 7 2013).

Second, the mixed method approach used presently is in-line with other

9 single-case research and offers a potential standard with which to validate

10 interventions as evidence-based (Barker et al., 2013). However, the lack of

11 observational data for both players and coach in training is a clear area for

12 improvement for future researchers. Whilst requiring sophisticated planning, the

13 results of the current study serve as a stimulus to conduct intervention work that

14 should more closely examine the behavior of a coach delivering his or her sessions,

15 and the responses of players to the coaching. As acknowledged by Harwood (2008),

16 it was impossible for the study to decipher which elements of the coaching

17 intervention possessed the greatest influence on players during each C-phase (e.g.,

18 perceived coach values; positive peer influence, specific session practices, pre/post-

19 session (de)briefing; positive coach reinforcement). Beyond our social validation

20 insights, our understanding of the most powerful mechanisms of influence within any

21 given phase remains constrained. Additionally, it would be prudent for future

22 researchers to conduct more in-depth qualitative investigations of players, parents and

23 coaches' experiences and perceptions of the intervention. In conjunction with

24 objective observational data, such qualitative insights would serve richer process

25 evaluations that could more appropriately inform intervention efficacy. Furthermore, 
1 in this present study we were not able to monitor the long-term effects of the

2 intervention through the use of a follow-up phase due to logistical and organization-

3 related challenges. Indeed, future researchers should consider follow-up assessment to

4 further glean information regarding intervention effectiveness and behavior change

5 (Barker et al.).

6 Third, the prospective order in which the intervention was delivered could also

7 have had an impact on the findings. The sequence of the 5C program was rationalized

8 on a basis of commencing with commitment and communication as core motivational

9 and interpersonal qualities before focusing on the more performance-based self-

10 regulatory attributes of concentration and control. Confidence received attention last

11 as it theoretically drew together a number of features from prior segments (Bandura,

12 1977). It is difficult to decipher the interactive effects of one phase upon another, and

13 if the results and participant experience of the intervention would change as a function

14 of order. Therefore, use of a group-based research design where each of the 5Cs is

15 delivered in a counterbalanced manner could potentially overcome this issue (see

16 Shadish, Cooke, \& Campbell, 2002) and extend our understanding of how to optimize

17 the intervention process for young athletes.

A final contextual consideration for future researchers is the consistency of

19 transfer of these psychosocial responses into matches and other sport settings.

20 Although some players articulated the transfer of their behavior into matches,

21 observations of both players and coach in team competition settings were beyond the

22 scope of the investigation. Therefore, although players' psychosocial profile of

23 responses by the end of the intervention promoted confidence that a learning effect

24 was taking place, future researchers are encouraged to assess psychosocial responses 
1 within and across sport settings (e.g., match performance; in alternate sport teams) to

2 address transferability and retention.

3 In conclusion, the current study adds to a growing number of investigations

4 that have explored and championed the strategic role of the coach in facilitating

5 psychosocial outcomes and life skills for young athletes (Camiré et al., 2011; Côté \&

6 Fraser-Thomas, 2007; Gould \& Carson, 2010). Whilst the role of parents in this study

7 was limited to third party observational reports, an implication and future direction for

8 practitioners and applied scholars is to involve parents as external assets more fully in

9 the psychosocial education process with coaches. Indeed, from an ecological

10 perspective, it would be interesting for future researchers to examine the combined

11 effects of 5C parent education, working in parallel to coach education, on the

12 psychological development and experience of young athletes. 


\section{References}

Bandura, A. (1977). Self-efficacy: Toward a unified theory of behavioral change. Psychological Review, 84, 191-215.

Barker, J. B., McCarthy, P. J., Jones, M. V., \& Moran, A. (2011). Single-case research methods in sport and exercise psychology. London: Routledge.

Barker, J. B., Mellalieu, S. D., McCarthy, P. J., Jones, M. V., \& Moran, A. (2013). A review of single-case research in sport psychology 1997-2012: Research trends and future directions. Journal of Applied Sport Psychology, 25, 4-32.

Benson, P.L. (1997). All kids are our kids: What communities must do to raise caring and responsible children and adolescents. San Francisco: Jossey-Bass.

Bronfenbrenner, U. (1999). Environments in developmental perspective: Theoretical and operational models. In S.L. Friedman \& T.D. Wachs (Eds.), Measuring environment across the life span: Emerging methods and concepts (pp. 3-28). Washington, DC: American Psychological Association.

Camiré, M., Forneris, T., Trudel, P., \& Bernard, D. (2011). Strategies for helping coaches facilitate positive youth development through sport.Journal of Sport Psychology in Action, 2, 92-99.

Côté, J, \& Fraser-Thomas, J. (2007). Youth involvement in sport. In P.R.E. Crocker (Ed.), Introduction to sport psychology: A Canadian perspective (pp. 266294). Toronto: Pearson Prentice Hall.

Cronbach, L.J., (1951). Coefficient alpha and the internal consistency of tests. Psychometrika, 16, 297-334.

Danish, S., Hodge, K., Heke, I., \& Taylor, T. (2003). Sport and childhood: Promoting healthy development of youth through physical activity and sport. In T.Gullota 
\& M. Bloom (Eds.), Encyclopedia of primary prevention and health promotion (pp. 1033-1040). New York; Kluwer.

Danish, S., Taylor, T., Hodge, K., \& Heke, I. (2004). Enhancing youth development through sport. World Leisure Journal, 46, 38-49.

Deci, E.L. \& Ryan, R.M. (1985). Intrinsic motivation and self-determination in human behavior. New York: Plenum Press.

Elliot, A.J. (1999). Approach and avoidance motivation and achievement goals. Educational Psychologist, 34, 169-189.

Fournier, J., Calmels, C., Durand-Bush, N., \& Salmela, J. (2005). Effects of a seasonlong PST program on gymnastic performance and on psychological skill development. International Journal of Sport and Exercise Psychology, 3, 59-77.

Fraser-Thomas, J., Côté, J., \& Deakin, J. (2005). Youth sport programs: An avenue to foster positive youth development. Physical Education and Sport Pedagogy, 10, $19-40$.

Gould, D., \& Carson, S. (2010). Coaching behaviours and developmental benefits of high school sports participation. Hellenic Journal of Psychology, 7, 298-314.

Gould, D., Damarjian, N., \& Medbery, R. (1999). An examination of mental skills training in junior tennis coaches. The Sport Psychologist, 13, 127-143.

Gould, D., Flett, R.M., \& Lauer, L. (2012). The relationship between psychosocial developmental and the sports climate experienced by underserved youth. Psychology of Sport and Exercise, 13, 80-87.

Harwood, C.G. (2008). Developmental consulting in a professional football academy: The 5Cs coaching efficacy program, The Sport Psychologist, 22, 109-133.

Harwood, C.G., \& Anderson, R., (2015). Coaching psychological skills in youth football: Developing the 5Cs. London: Bennion-Kearney. 
1 Harwood, C.G., \& Swain, A.B. (2002). The development and activation of achievement goals in tennis: II. A player, parent and coach intervention. The Sport Psychologist, 16, 111-137.

Holland, M. J., Woodcock, C., Cumming, J., \& Duda, J. L. (2010). Mental qualities and employed mental techniques of young elite team sport athletes. Journal of Clinical Sport Psychology, 4, 19-38.

Holt, N.L., \& Dunn, J.G.H. (2004). Toward a grounded theory of the psychosocial competencies and environmental conditions associated with soccer success. Journal of Applied Sport Psychology, 16, 199-219.

Hrycaiko, D. W. \& Martin, G. L. (1996). Applied research studies with single-subject designs: Why so few? Journal of Applied Sport Psychology, 8, 183-199.

Johnston, J., Harwood, C., \& Minniti, A. M. (2013). Positive Youth Development in Swimming: Clarification and Consensus of Key Psychosocial Assets. Journal of Applied Sport Psychology, 25, 392-411.

Johnson, J. J., Hrycaiko, D. W., Johnson, G. V., \& Halas, J. M. (2004). Self-talk and female youth soccer performance. The Sport Psychologist, 18, 44-59.

Jones, M. I., \& Lavallee, D. (2009). Exploring the life skills needs of British adolescent athletes. Psychology of Sport and Exercise, 10, 159-167.

Lerner, R. M., Fisher, C. B., \& Weinberg, R. A. (2000). Toward a science for and of the people: Promoting civil society through the application of developmental science. Child Development, 71, 11-20.

MacNamara, A.,Button, A. \& Collins, D. (2010a). The role of psychological characteristics in facilitating the pathway to elite performance. Part 1: Identifying mental skills and behaviours. The Sport Psychologist, 24, 52-73. 
1 MacNamara, Á., Button, A., \& Collins, D. (2010b). The role of psychological characteristics in facilitating the pathway to elite performance. Part 2: Examining environmental and stage-related differences in skills and behaviors. The Sport Psychologist, 24, 1 74-96.

Mamassis, G., \& Doganis, G. (2004). The effects of a mental training program on juniors pre-competitive anxiety, self-confidence, and tennis performance. Journal of Applied Sport Psychology, 16, 118-137.

Martin, G., \& Pear, J. (2003). Behaviour modification: What it is and how to do it (7th ed.). Englewood Cliffs, NJ: Prentice-Hall.

Martin, G.L., \& Toogood, A. (1997). Cognitive and behavioral components of a seasonal psychological skills training program for competitive figure skaters. Cognitive and Behavioral Practice, 4, 383-404.

Nicholls, J.G. (1989). The competitive ethos and democratic education. Cambridge, MA: Harvard University Press.

Nideffer, R.M., \& Sharpe, R. (1978). A.C.T.: Attention control training. New York: Wyden Books.

Page, J., \& Thelwell, R. (2013). The value of social validation in single-case methods in sport and exercise psychology. Journal of Applied Sport Psychology, 25, 6171. doi: 10.1080/10413200.2012.663859

Pain, M.A., \& Harwood, C.G. (2004). Knowledge and perceptions of sport psychology within English soccer. Journal of Sports Sciences, 22, 813-826.

Petitpas, A., Cornelius, A., Van Raalte, J., \& Jones, T. (2005). A framework for planning youth sport programs that foster psychosocial development. The Sport Psychologist, 19, 63-80. 
1 Shadish, W. R., Cook, T. D., \& Campbell, D. T. (2002). Experimental and quasi experimental designs for generalized causal inference ( $2^{\text {nd }}$ ed.). Boston: Houghton-Mifflin.

Sheard, M., \& Golby, J. (2006). Effect of a psychological skills training program on swimming performance and positive psychological development. International Journal of Sport and Exercise Psychology,4, 149-169.

Smith, R.E., \& Johnson, J. (1990). An organizational empowerment approach to consultation in professional baseball. The Sport Psychologist, 4, 347-357.

Smith, R. E., \& Smoll, F. L. (1997). Coaching the coaches: Youth sports as a scientific and applied behavioral setting. Current Directions in Psychological Science, 6, 16-21.

Smith, R.E., Smoll, F.L.., \& Cumming, S.P. (2007). Effects of a motivational climate intervention for coaches on young athletes' sport performance anxiety. Journal of Sport and Exercise Psychology, 29, 39-59.

Strachan, L., Côté, J., \& Deakin, J. (2011). A new view: Exploring positive youth development in elite sport contexts. Qualitative Research in Sport, Exercise and Health, 3, 9-32. DOI: 10.1080/19398441.2010.541483

Thelwell, R., Greenlees, I., \& Weston, N. (2006). Using psychological skills training to develop soccer performance. Journal of Applied Sport Psychology, 18, 254270.

Vealey, R. S. (1988). Future directions in psychological skills training. The Sport Psychologist. 2, 318-336.

Vella, S., Oades, L., \& Crowe, T. (2011). The role of the coach in facilitating positive youth development: Moving from theory to practice. Journal of Applied Sport Psychology, 23, 33-48. 
1 Figure 1. Player 1 Perceptions of 5C use

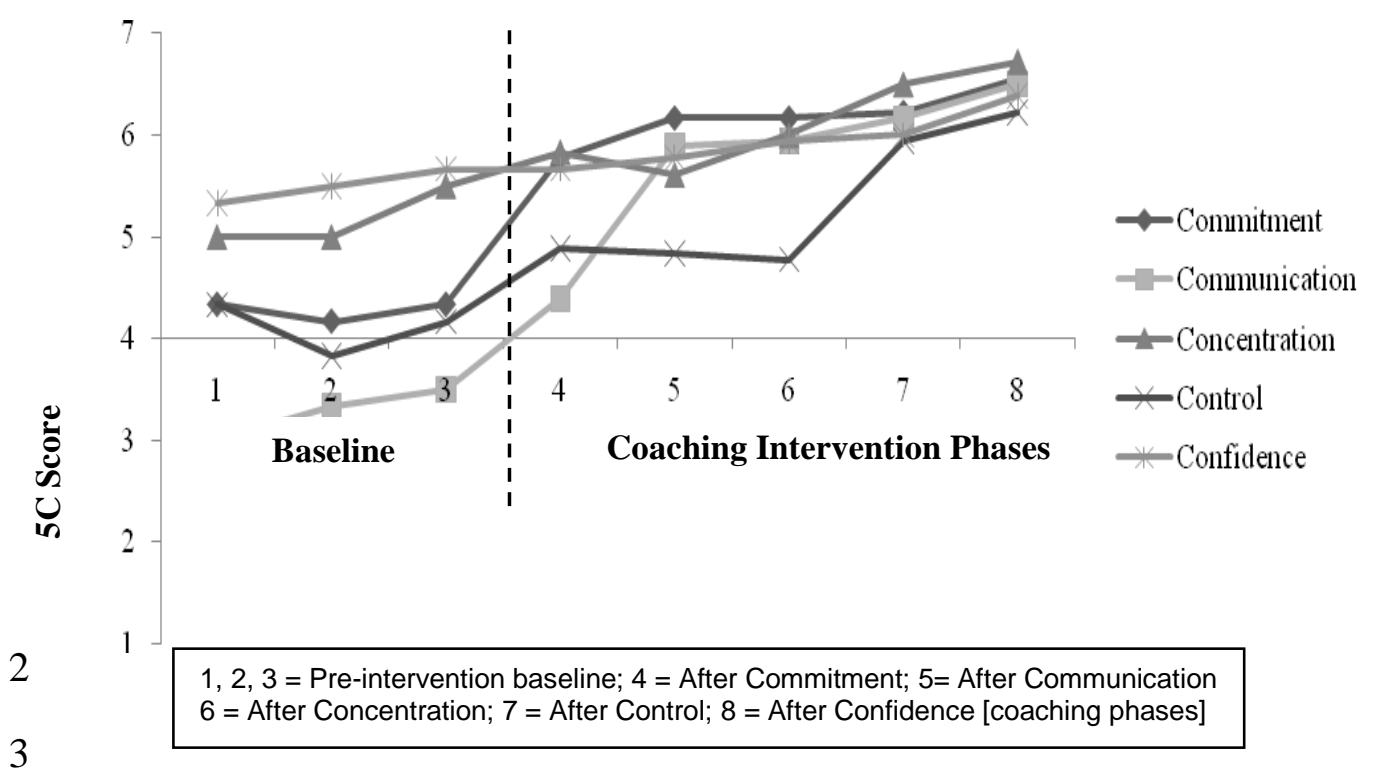

4

5 Figure 2. Player 2 Perceptions of 5C use

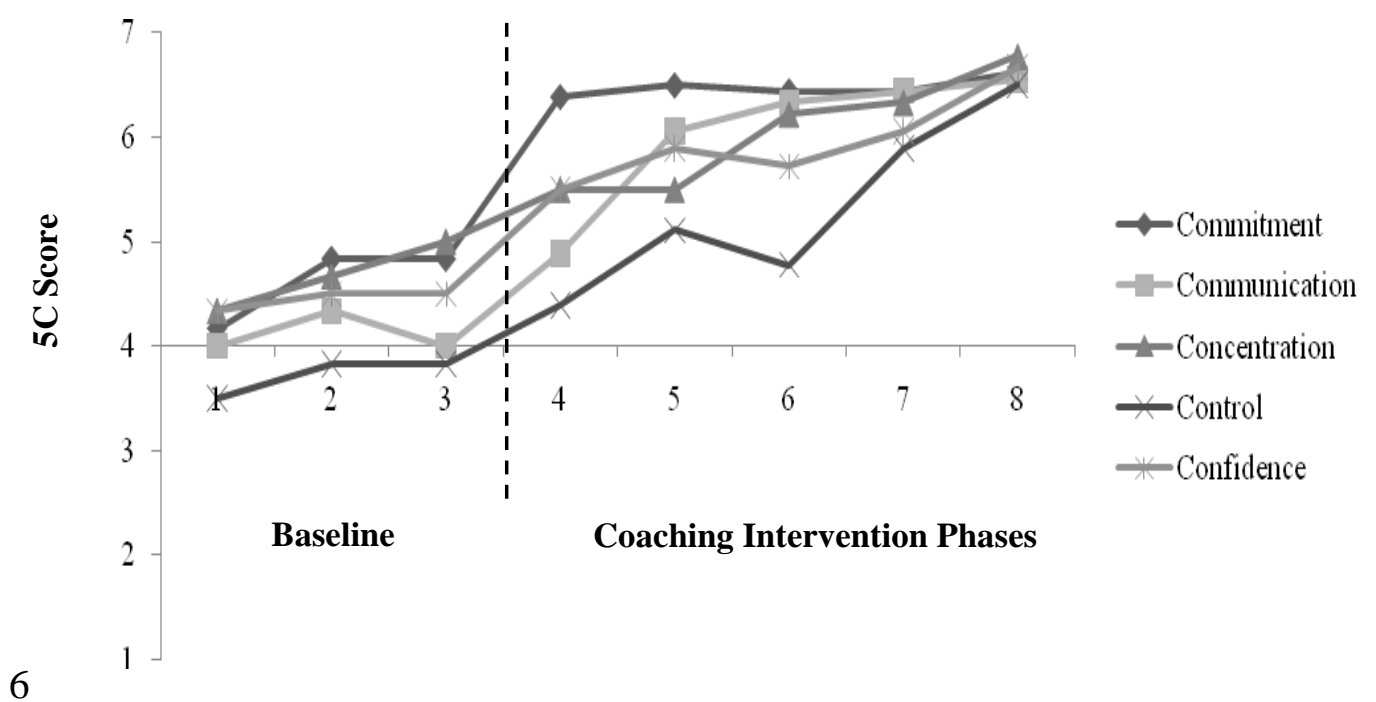


1 Figure 3. Player 3 Perceptions of 5C use

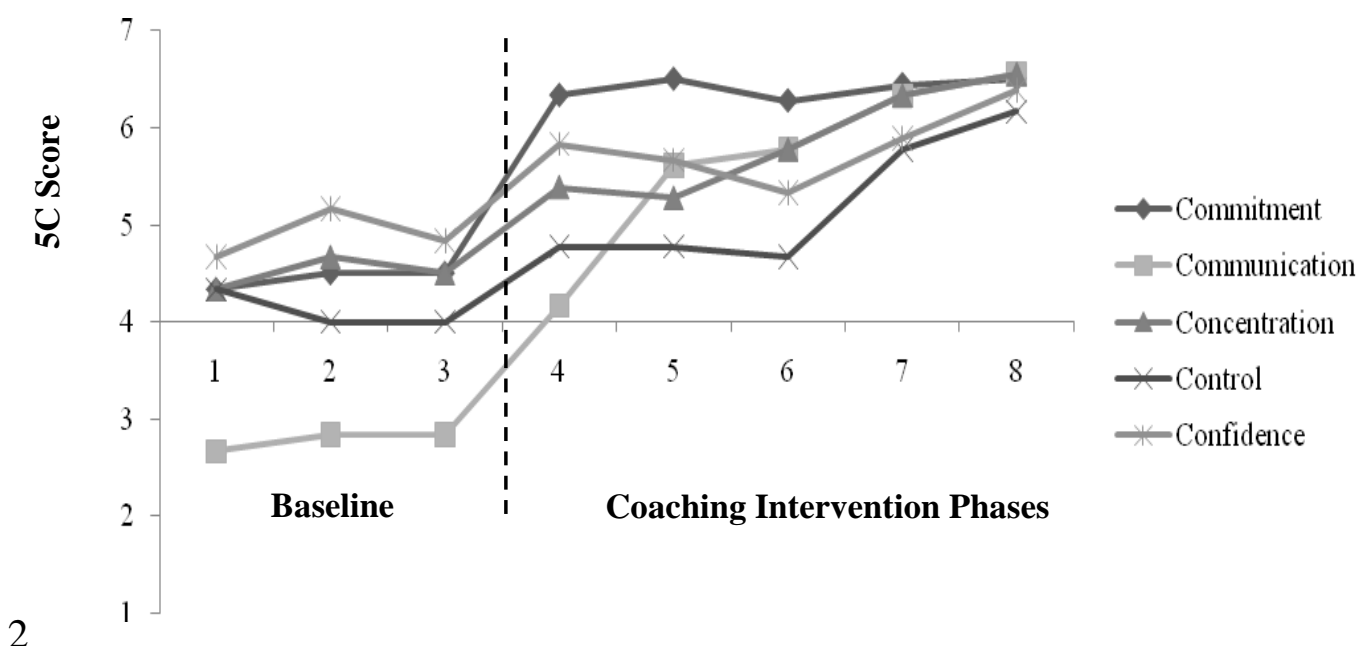

3 Figure 4. Player 4 Perceptions of 5C use

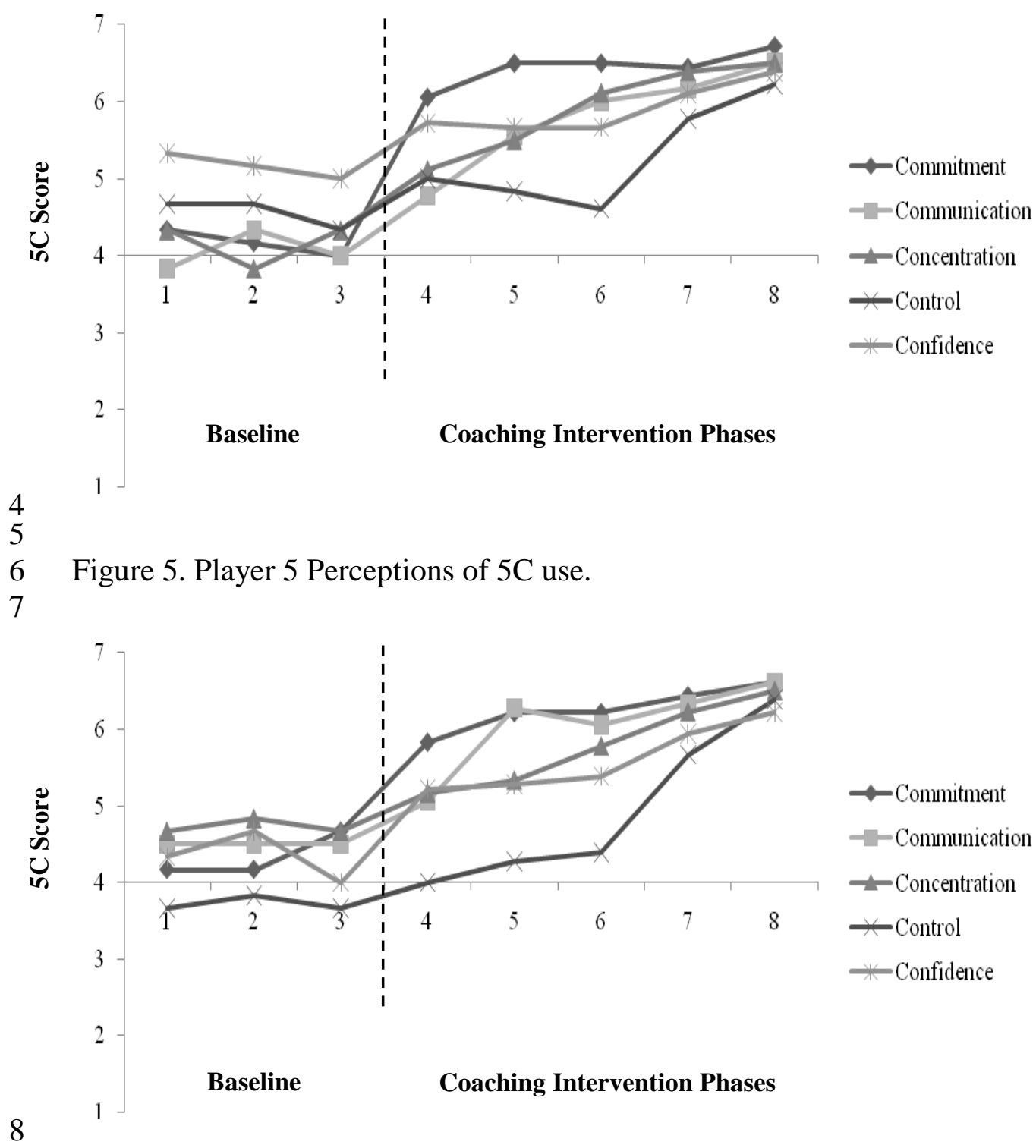


1 Table 1. 5C Coaching Behavior Guidelines

2

1. Intentionally promote a particular psychological skill and behavior with the same importance one would give to a technical or physical skill

2. Increase awareness of what the skill or attribute comprises by differentiating good and bad examples of behavior to players

3. Emphasise the positive value of possessing the skill or attribute to players

4. Role model behaviors associated with the skill or attribute at all times and employ role model examples in sessions with players

5. Structure the session in a manner that helps teach and train the skill, and give players responsibility to practice the skills and behaviors in drills

6. Publicly reinforce those players who respond by demonstrating the targeted skill or behavior

7. Employ peer reinforcement of targeted skill (e.g. buddy system) and subsequently reinforce those players who support their peers

8. Review the presence of the skill and levels of behavior throughout the session and at the end using coach, player and peer review and debriefing

Reprinted with permission from Harwood (2008) 
1

2 Table 2. Players 5C Perceptions: Pre and Post-Intervention

\begin{tabular}{lccccc}
\hline Dependent Variables & Player 1 & Player 2 & Player 3 & Player 4 & Player 5 \\
& & & & & \\
\hline Commitment-Pre & $4.28 \pm$ & $4.50 \pm$ & $4.44 \pm$ & $4.17 \pm$ & $4.33 \pm$ \\
$(\mathrm{m} \pm \mathrm{s})$ & 0.10 & 0.33 & 0.10 & 0.17 & 0.29 \\
& & & & & \\
Commitment-Post $(\mathrm{m} \pm$ & $6.18 \pm$ & $6.48 \pm$ & $6.41 \pm$ & $6.44 \pm$ & $6.27 \pm$ \\
s) & 0.28 & 0.08 & 0.10 & 0.24 & 0.29
\end{tabular}

Communication-Pre (m

$\pm s)$

$3.28 \pm$

$4.11 \pm$

$2.78 \pm$

0.19

0.10

$4.06 \pm$

$4.50 \pm$

0.25

$5.78 \pm$

$6.06 \pm$

$5.69 \pm$

0.68

0.94

$5.80 \pm$

0.67

$6.07 \pm$

$(\mathrm{m} \pm s)$

0.81

$5.17 \pm$

0.29

$4.67 \pm$

0.33

$4.50 \pm$

0.17

$4.17 \pm$

0.29

$4.72 \pm$

s)

$6.13 \pm$
0.46

$6.07 \pm$

$5.87 \pm$

$5.92 \pm$

s)

Concentration-Post ( $\mathrm{m} \pm$

0.56

0.56

0.60

$5.80 \pm$

0.57

$\begin{array}{cccccc}\text { Confidence-Pre }(\mathrm{m} \pm s) & 5.50 \pm & 4.44 \pm & 4.89 \pm & 5.17 \pm & 4.33 \pm \\ & 0.17 & 0.10 & 0.25 & 0.17 & 0.33\end{array}$

$\begin{array}{llllll}\text { Confidence-Post }(\mathrm{m} \pm s) & 5.96 \pm & 5.97 \pm & 5.82 \pm & 5.91 \pm & 5.61 \pm\end{array}$

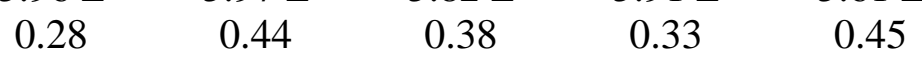


1 Table 3. Means and Percentages Illustrating Phase Changes from Total Baseline to Presentation of Specific 5C Intervention

\begin{tabular}{|c|c|c|c|c|c|c|c|c|c|c|c|c|c|c|c|}
\hline & $\begin{array}{l}\text { Player } \\
1\end{array}$ & $\begin{array}{l}\text { Parent } \\
1 \\
\end{array}$ & $\begin{array}{l}\text { Coach } \\
1\end{array}$ & $\begin{array}{l}\text { Player } \\
2\end{array}$ & $\begin{array}{l}\text { Parent } \\
2\end{array}$ & $\begin{array}{l}\text { Coach } \\
2\end{array}$ & $\begin{array}{l}\text { Player } \\
3\end{array}$ & $\begin{array}{l}\text { Parent } \\
3 \\
\end{array}$ & $\begin{array}{l}\text { Coach } \\
3 \\
\end{array}$ & $\begin{array}{l}\text { Player } \\
4\end{array}$ & $\begin{array}{l}\text { Parent } \\
4\end{array}$ & $\begin{array}{l}\text { Coach } \\
4\end{array}$ & $\begin{array}{l}\text { Player } \\
5 \\
\end{array}$ & $\begin{array}{l}\text { Parent } \\
5\end{array}$ & $\begin{array}{l}\text { Coach } \\
5\end{array}$ \\
\hline \multicolumn{16}{|l|}{ Commitment } \\
\hline Baseline (m) & 4.28 & 4.44 & 3.50 & 4.61 & 4.94 & 4.72 & 4.44 & 5.00 & 4.61 & 4.17 & 4.06 & 3.56 & 4.33 & 4.44 & 4.78 \\
\hline Phase (m) & 5.78 & 5.94 & 5.44 & 6.89 & 6.17 & 6.44 & 6.33 & 6.50 & 5.83 & 6.06 & 6.00 & 5.89 & 5.83 & 5.83 & 5.94 \\
\hline \% change & 35.1 & 33.7 & 55.4 & 38.6 & 24.8 & 36.4 & 42.4 & 30.0 & 26.4 & 45.4 & 47.9 & 65.7 & 34.5 & 33.7 & 24.3 \\
\hline \multicolumn{16}{|c|}{ Communication } \\
\hline Baseline (m) & 3.28 & 4.44 & 2.44 & 4.11 & 4.28 & 3.89 & 2.78 & 4.61 & 3.22 & 4.06 & 5.11 & 3.72 & 4.50 & 4.44 & 3.28 \\
\hline Phase (m) & 5.89 & 6.00 & 5.61 & 6.06 & 6.11 & 6.00 & 5.61 & 6.06 & 5.83 & 5.56 & 5.83 & 5.89 & 6.28 & 6.39 & 5.94 \\
\hline$\%$ change & 79.6 & 35.0 & 129.5 & 47.4 & 42.8 & 54.3 & 102.0 & 31.4 & 26.4 & 37.1 & 14.1 & 65.7 & 34.5 & 35.0 & 24.3 \\
\hline \multicolumn{16}{|l|}{ Concentration } \\
\hline Baseline (m) & 5.17 & 4.44 & 4.00 & 4.67 & 4.28 & 4.17 & 4.50 & 4.61 & 4.22 & 4.17 & 5.11 & 3.89 & 4.72 & 4.44 & 4.44 \\
\hline Phase (m) & 6.00 & 6.00 & 6.00 & 6.22 & 6.00 & 6.17 & 5.78 & 5.78 & 6.06 & 6.11 & 6.33 & 6.06 & 5.78 & 6.39 & 5.89 \\
\hline$\%$ change & 16.1 & 35.0 & 50.0 & 33.3 & 40.3 & 48.1 & 28.4 & 25.3 & 43.5 & 46.6 & 23.8 & 55.8 & 22.4 & 35.0 & 32.5 \\
\hline \multicolumn{16}{|l|}{ Control } \\
\hline Baseline (m) & 4.11 & 4.56 & 2.61 & 3.72 & 3.67 & 3.06 & 4.11 & 3.44 & 3.61 & 4.56 & 4.78 & 4.06 & 3.72 & 4.56 & 3.78 \\
\hline Phase (m) & 5.94 & 5.83 & 5.83 & 5.89 & 5.83 & 5.78 & 5.78 & 5.61 & 5.78 & 5.78 & 5.89 & 5.89 & 5.67 & 5.61 & 5.94 \\
\hline$\%$ change & 44.5 & 28.0 & 123.3 & 58.2 & 59.0 & 89.2 & 40.6 & 62.9 & 60.1 & 26.9 & 23.3 & 60.1 & 52.3 & 28.0 & 57.2 \\
\hline \multicolumn{16}{|l|}{ Confidence } \\
\hline Baseline (m) & 5.50 & 4.89 & 4.06 & 4.44 & 4.50 & 4.39 & 4.89 & 4.56 & 4.22 & 5.17 & 5.11 & 4.56 & 4.33 & 4.89 & 4.33 \\
\hline Phase (m) & 6.39 & 6.11 & 6.44 & 6.67 & 6.61 & 6.67 & 6.39 & 6.22 & 6.39 & 6.39 & 6.61 & 6.44 & 6.22 & 6.11 & 6.61 \\
\hline$\%$ change & 16.2 & 25.0 & 58.8 & 50.1 & 46.9 & 52.0 & 30.7 & 36.5 & 51.4 & 23.7 & 29.3 & 41.4 & 43.5 & 25.0 & 52.5 \\
\hline
\end{tabular}


1 Table 4. Combined 5C Psychosocial Profiles from final baseline (Time 3) to the end

2 of the study (Time 8)

\begin{tabular}{ccc}
\hline Participant & $\begin{array}{c}\text { Baseline Time 3 } \\
\text { (Mean, SD) }\end{array}$ & $\begin{array}{c}\text { Post-Intervention Time 8 } \\
\text { (Mean, SD) }\end{array}$ \\
Player 1 & $4.63 \pm 0.92$ & $6.48 \pm 0.19$ \\
Parent 1 & $4.53 \pm 0.30$ & $6.32 \pm 0.19$ \\
Coach 1 & $2.70 \pm 1.49$ & $6.41 \pm 0.14$ \\
& $4.37 \pm 0.46$ & $6.62 \pm 0.11$ \\
Player 2 & $4.27 \pm 0.58$ & $6.54 \pm 0.12$ \\
Parent 2 & $4.07 \pm 0.50$ & $6.53 \pm 0.13$ \\
Coach 2 & $4.13 \pm 0.79$ & $6.43 \pm 0.16$ \\
Player 3 & $4.23 \pm 0.79$ & $6.27 \pm 0.23$ \\
Parent 3 & $4.00 \pm 0.53$ & $6.38 \pm 0.16$ \\
Coach 3 & $4.33 \pm 0.41$ & $6.47 \pm 0.18$ \\
& $4.77 \pm 0.38$ & $6.50 \pm 0.13$ \\
Player 4 & $4.00 \pm 0.42$ & $6.48 \pm 0.14$ \\
Parent 4 & $4.30 \pm 0.45$ & $6.47 \pm 0.16$ \\
Coach 4 & $4.70 \pm 0.32$ & $6.33 \pm 0.22$ \\
Player 5 & $4.10 \pm 0.57$ & $6.51 \pm 0.15$ \\
Parent 5 & & \\
Coach 5 & & \\
& &
\end{tabular}

